\title{
The sterol carrier protein 2/3-oxoacyl-CoA thiolase (SCPx) is involved in cholesterol uptake in the midgut of Spodoptera litura: gene cloning, expression, localization and functional analyses Xing-Rong Guo ${ }^{1,2}$, Si-Chun Zheng1, Lin Liu ${ }^{1}$ and Qi-Li Feng*1
}

Address: ${ }^{1}$ Guangdong Provincial Key Lab of Biotechnology for Plant Development, School of Life Sciences, South China Normal University, Guangzhou, 510631, PR China and 2The Faculty of Pharmacy and Laboratory Medicine, Yunyang Medical College, Hubei, 442000, PR China

Email: Xing-Rong Guo - gxrdl@126.com; Si-Chun Zheng - sczheng@scnu.edu.cn; Lin Liu - liul@scnu.edu.cn; Qi-Li Feng* - qlfeng@scnu.edu.cn * Corresponding author

Published: 13 November 2009

BMC Molecular Biology 2009, 10:102 doi:10.1186/147I-2199-10-102
Received: 5 June 2009

Accepted: 13 November 2009

This article is available from: http://www.biomedcentral.com/I47/-2/99/10/102

(c) 2009 Guo et al; licensee BioMed Central Ltd.

This is an Open Access article distributed under the terms of the Creative Commons Attribution License (http://creativecommons.org/licenses/by/2.0), which permits unrestricted use, distribution, and reproduction in any medium, provided the original work is properly cited.

\begin{abstract}
Background: Sterol carrier protein-2/3-oxoacyl-CoA thiolase (SCPx) gene has been suggested to be involved in absorption and transport of cholesterol. Cholesterol is a membrane component and is a precursor of ecdysteroids, but cannot be synthesized de novo in insects. However, a direct association between SCPX gene expression, cholesterol absorption and development in lepidopteran insects remains to be experimentally demonstrated.

Results: An SCPx cDNA (SISCPx) cloned from the common cutworm, Spodoptera litura, was characterized. The SISCPx cDNA encoded a 535-amino acid protein consisting of a 3-oxoacyl-CoA thiolase (SCPx-t) domain and a SCP-2 (SCPx-2) domain. SISCPx mRNA was expressed predominately in the midgut, while SISCPx-2 mRNA was detected in the midgut, fat body and epidermis and no SISCPx-t mRNA was detected. A 58-kDa full-length SCPx protein and a 44-kDa $S C P x-t$ protein were detected in the midgut of sixth instar larvae when the anti-SISCPx-t antibody was used in western blotting analysis; a 16-kDa SCP-2 protein was detected when anti-SISCPx-2 antibody was used. SISCPx protein was post-translationally cleaved into two smaller proteins, $S C P x-t$ and SCPx-2. The gene appeared to be expressed into two forms of mRNA transcripts, which were translated into the two proteins, respectively. SISCPx-t and SISCPx-2 proteins have distinct and different locations in the midgut of sixth instar larvae. SISCPX and SISCPx-t proteins were detected predominately in the cytoplasm, whereas SISCPX-2 protein was detected in the cytoplasm and nuclei in the Spli-22I cells. Over-expression of SISCPX and SISCPX-2 proteins enhanced cholesterol uptake into the Spli-22I cells. Knocking-down SISCPx transcripts by dsRNA interference resulted in a decrease in cholesterol level in the hemolymph and delayed the larval to pupal transition.
\end{abstract}

Conclusion: Spatial and temporal expression pattern of this SISCPx gene during the larval developmental stages of $S$. litura showed its specific association with the midgut at the feeding stage. Over-expression of this gene increased cholesterol uptake and interference of its transcript decreased cholesterol uptake and delayed the larval to pupal metamorphosis. All of these results taken together suggest that this midgut-specific SISCPx gene is important for cholesterol uptake and normal development in S. litura. 


\section{Background}

Sterol carrier protein 2/3-oxoacyl-CoA thiolase (SCPx) belongs to a well-characterized SCP-2 gene family [1], whose members encode an intracellular non-specific lipid carrier protein. SCP-2 is present in both vertebrates and invertebrates and is involved in intracellular sterol/lipid transfer processes, which affect biosynthesis and metabolism of fatty acids and sterols [2]. In insects, cholesterol is required for cellular membranes and ecdysteroid biosynthesis. Insects utilize phytols, such as $\beta$-sitosterol, campesterol and stigmasterol, and synthesize ecdysteroids (molting hormone) in the prothoracic glands [3]. However, insects cannot synthesize cholesterol via de novo biosynthesis because they lack at least two key enzymes, squalene monooxygenase and lanosterol synthase, in their system [4,5]. Therefore insects must obtain cholesterol or other sterols from their diet to fulfill their sterol requirements for normal growth, development and reproduction [1,6-8]. In humans [9], mice [10], rats [11] and chickens [12], a single SCPx gene encodes a fusion protein containing 3-oxoacyl-CoA thiolase (SCPx-t) and SCPx-2 domains, which are post-translationally cleaved into two separate proteins. The SCPX-t protein functions as a 3oxoacyl-CoA thiolase in peroxisomal oxidation of branched-chain fatty acids [13]. The SCP-2 protein is released from the peroxisomes into the cytoplasm and then translocated into the nucleus, where it acts as a transcription factor [14]. This gene is also transcribed into a transcript that encodes only the SCP-2 protein depending on alternative transcription initiation $[9-12,15,16]$. In invertebrates, members of the SCP-2 gene family have been reported in many species. In Caenorhabditis elegans, the genes encoding 3-oxoacyl-CoA thiolase (SCPx-t) and SCP-2 protein are not fused together and the two proteins are encoded by separate genes, $\mathrm{P} 44$, which is a thiolasetype protein homologous to the $N$-terminal protein SCPX$\mathrm{t}$ of the vertebrate SCPx, and UNC-24, which is homologous to the $C$-terminal SCPX-2 protein of the vertebrate SCPx $[17,18]$. In Aedes aegypti and Drosophila melanogaster the SCPx genes encode a SCPx transcript of mRNA that encodes both SCPx-t and SCPx-2 domains [19,20], while there are separate genes producing other low-molecularmass SCP-2 proteins in A. aegypti [2]. In the lepidopteran insects Bombyx mori and Spodoptera littoralis, the SCPx gene also encodes two fused SCPX-t and SCP-2 domains $[21,22]$.

SCPx deletion mutant mice accumulated a derivative of the intermediate 24-keto-trihydroxy cholestanoic acidCoA (24-keto-THCA-CoA), suggesting that the products of the SCPx gene are responsible for the cleavage of 24keto-THCA-CoA into choloyl-CoA [13]. Over-expression of SCPx in mouse L-cells significantly altered cholesterol absorption and metabolism [23]. Knocking down AeSCP2 transcript decreased the accumulated level of cholesterol in the pupae and resulted in increased mortality of the mosquito A. aegypti adults, indicating that the AeSCP-2 gene is critical for adult development [24]. In transfected mouse L-cells SCPx/SCP-2 co-localized with catalase in peroxisomes, but significant amounts of SCPx/SCP-2 appeared to be extra-peroxisomal $[1,23]$. In both in vitro cultured cells and the larval midgut of $A$. aegypti, AeSCPx was present mostly in the peroxisomes, while AeSCP-2, which is not transcribed from AeSCPx gene in A. aegypti cells [20], was present in the cytosol, mitochondria and nuclei [25]. The difference in the subcellular distribution of SCPX and SCPX-2 suggests that these two proteins may play different and specific roles in cellular processes.

In the present study, cloning, characterization, cellular localization and functional analysis of a SCPx cDNA in Spodoptera litura were described. SlSCPx is predominately expressed in the midgut during the larval feeding stage. Knocking down SlSCPx transcripts in larvae and overexpressing SlSCPx and SlSCPX-2 in the Spli-221 cell line altered the accumulation of cholesterol and adversely affected the larval to pupal transition. All of these results taken together suggest that the SISCPx gene plays an important role in cholesterol uptake as well as growth and development of S. litura.

\section{Results \\ Cloning and characterization of SISCPx cDNA sequence}

A SCPX cDNA sequence was identified by randomly picking and sequencing cDNA clones in an expression library constructed with mRNA isolated from the midgut of 3day-old $6^{\text {th }}$ instar larvae of S. litura. This cDNA (SlSCPx) contained 1,938 bp in length encoding an open reading frame (ORF) of 535-amino acids with an estimated molecular mass of $58 \mathrm{kDa}$, which included two domains, one containing 390-amino acid residues with an estimated molecular mass of $41 \mathrm{kDa}$ at the $N$-terminal end and the other containing 145-amino acid residues with an estimated molecular mass of $16 \mathrm{kDa}$ at the $C$-terminal end (Fig. 1). Blast search in the GenBank database indicated that the first domain was highly homologous to 3-oxoacyl-CoA thiolase, while the second domain was highly homologous to SCP-2 protein in other species. For the sake of convenience in this paper, the full-length protein is referred to as SlSCPx; the 3-oxoacyl-CoA thiolase domain is referred to as SISCPX-t; and the SCP-2 domain is referred to as SlSCPX-2 (Fig. 1). To confirm and obtain the SISCPx full-length CDNA directly from the $S$. litura midgut, reverse-transcription PCR (RT-PCR) was performed using a pair of primers designed on the basis of the cloned SISCPx cDNA sequence (Fig. 1 and 2A) and mRNA extracted from the midgut of 3-day-old $6^{\text {th }}$ instar larvae. Interestingly, two PCR products of approximately $1.6 \mathrm{~kb}$ and $0.6 \mathrm{~kb}$ were obtained (Fig. $2 \mathrm{~B}$ ). The results of sequencing and Blast search indicated that they encoded a 




Figure I

Nucleotide and deduced amino acid sequences of S. litura SISCPx cDNA. The numbers on the left are for nucleotide sequence and the numbers on the right are for the amino acid sequences. The thiolase domain (SISCPx-t) is shown in Italy letters and the SISCPX-C (SCP2) domain is indicated by bolded letters. The peroxisome targeting sequence (SKL) is indicated in a square. The forward and reverse primers used for RT-PCR amplification of the full length cDNA from mRNA are underlined. A cysteine residue (Cys82) is shown in grey background, which has been suggested to be part of the active site in a $Z$. ramigera 3-oxoacyl-CoA thiolase. The terminal codon is indicated with asterisks below the codon. The GenBank accession number of this cDNA is Fj986464.

full-length SCPx protein, which included both SCPx-t and SCPX-2 domains, and a SCP-2 protein, respectively. Sequence comparison of the SlSCPx cDNA with the sequences of the two PCR products revealed that the PCR product SCPx $(1.6 \mathrm{~kb})$ was identical to the SISCPx fulllength cDNA cloned from the screening of the library, while the SCPx-2 cDNA (0.6-kb) was identical to the Cterminal SlSCPX-2 domain of the SlSCPx CDNA, but lacked the $N$-terminal SCPx-t sequence between the 43 and 1,168 nucleotides of the sequence. Similar results were observed for transcripts of SCPx/2 gene in B. mori, where two transcripts approximately 1.7 - and $0.6-\mathrm{kb}$ cDNA products were amplified by RT-PCR [22].

The deduced SlSCPx protein shared the same domain architecture as that of the vertebrate SCPX: a thiolase (SCPX-t) at the N-terminal region and a SCPX-2 domain at the $C$-terminal region (Fig. 1). The $C$-terminal regions of the SlSCPX protein and the SISCPX-2 protein contained a peroxisomal-targeting signal Ser-Lys-Leu. It is likely that SlSCPx and SlSCPX-2 proteins can be transported to peroxisomes where they perform their functions. A cysteine residue (Cys82) (Fig. 1A), corresponding to the catalytically active cysteine in Zoogloea ramigera 3-ketoacyl-CoA thiolase [26], was conserved in the SlSCPx protein.

Blast search analysis indicated that SISCPx protein was a member of the SCP-2 gene family and highly similar to SCPx in other species, such as SCPx (99\%) of S. littoralis Boisduval [21], which is a geographically isolated allopatric species of $S$. litura Fabricius (CABI and EPPO, 1990), $B$. mori SCPx (88\%) [22], A. aegypti SCPx (60\%) [20], D. melanogaster SCPx (63\%) [19], O. cuniculus SCPx (55\%) [27], Mus musculus SCPx (55\%) [23] and Homo sapiens SCPx (54\%) [9] (Fig. 3A). This indicates that this gene is wellconserved during evolution and it may play a conserved 


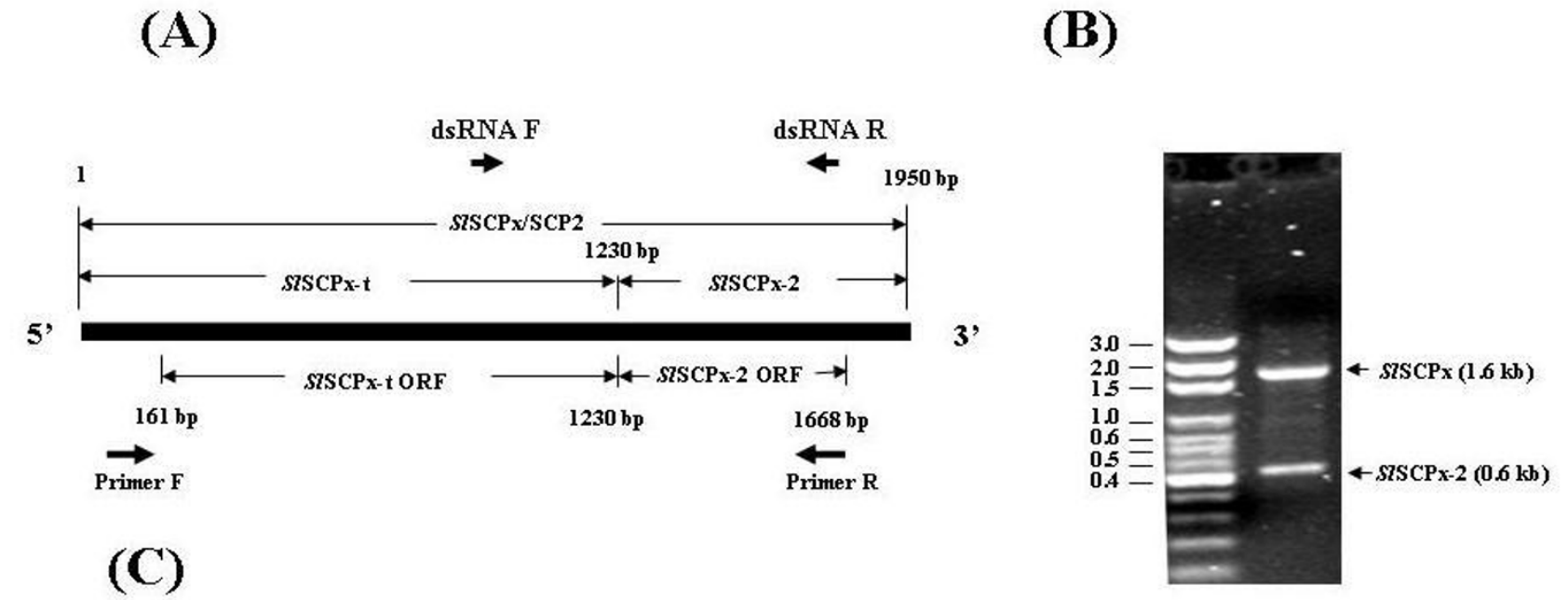

\section{(B)}

STSCPX mRNA (1 .6 kb)

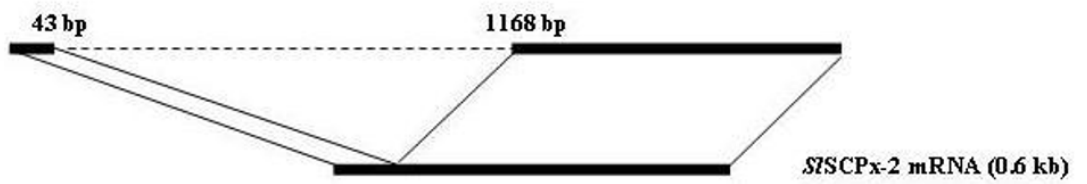

Figure 2

RT-PCR amplification strategy of S. litura SISCPx cDNA from mRNA. (A) RT-PCR amplification strategy, PCR-amplified products (B) and diagram of alternative splicing of SISCPx transcripts (C). The positions of the forward and reverse primers for RT-PCR are indicated in arrows below the sequence diagram. The arrows above the sequence diagram show the position of primers for the SISCPx dsRNA preparation (A). The two PCR products were amplified and their sizes were I.6 kb for the full-length SISCPx and $0.6 \mathrm{~kb}$ for the SISCPx-C region, respectively (B). The dotted line shows the deleted SISCPx-t fragmentfrom the $\mathrm{N}$-terminal (43 to I, I68 nucleotides) of SISCPx sequence, as compared to SISCPx- 2 .

functional role in growth and development of insects. Although the lepidopteran SCPx have higher identities to the dipteran SCPx in regard to their amino acid sequence and they are clustered into an insect group, the lepidopteran SCPX appeared to be orthologs of the vertebrate SCPx (Fig. 3B).

\section{In vitro expression of SISCPx, SISCPx-t, SISCPx-2 recombinant proteins}

In vitro expression of the SlSCPx (full-length protein), SISCPx-t (the SCPx-t domain at the N-terminus) and SlSCPx2 (the SCP-2 domain at the $C$-terminus) proteins respectively were achieved in a bacterial expression system and the recombinant His-tagged fusion proteins were purified using His-tag affinity columns (Fig. 4A). The resultant proteins had the identical molecular mass as predicted based on the deduced amino acid sequences. Antibodies against these three peptides, respectively, were generated and could specifically recognize and distinguish the recombinant proteins from each other in western blotting analyses (Fig. 4B-D).

\section{Temporal and spatial expression of SISCPx gene}

When a DNA fragment at the SlSCPx-2 domain region of the SISCPX gene was used as a probe, three mRNA transcripts $(2.8,2.0$ and $0.9 \mathrm{~kb})$ were detected in the midgut of different stages (Fig. 5A). They appeared to be the transcripts encoding SlSCPx (2.8 kb and $2.0 \mathrm{~kb})$ and SISCPX-2 (0.9 kb) mRNA, respectively. The $2.8-\mathrm{kb}$ and $2.0-\mathrm{kb}$ transcripts of SlSCPx were probably the pre-mature and mature mRNA products of the gene, respectively [23] and they were highly and specifically expressed in the midgut (Fig. 5A). In contrast, the SISCPx-2 mRNA $(0.9 \mathrm{~kb})$ was also detected in the fat body and epidermis in addition to the midgut during larval and pupal development (Fig. 5A and $5 \mathrm{~B}$ ). In the midgut, the expression of the SlSCPx transcripts was much higher during the larval feeding stages (for example, days 1 to 2 of $5^{\text {th }}$ instar and days 1 to 3 of $6^{\text {th }}$ 
(A)

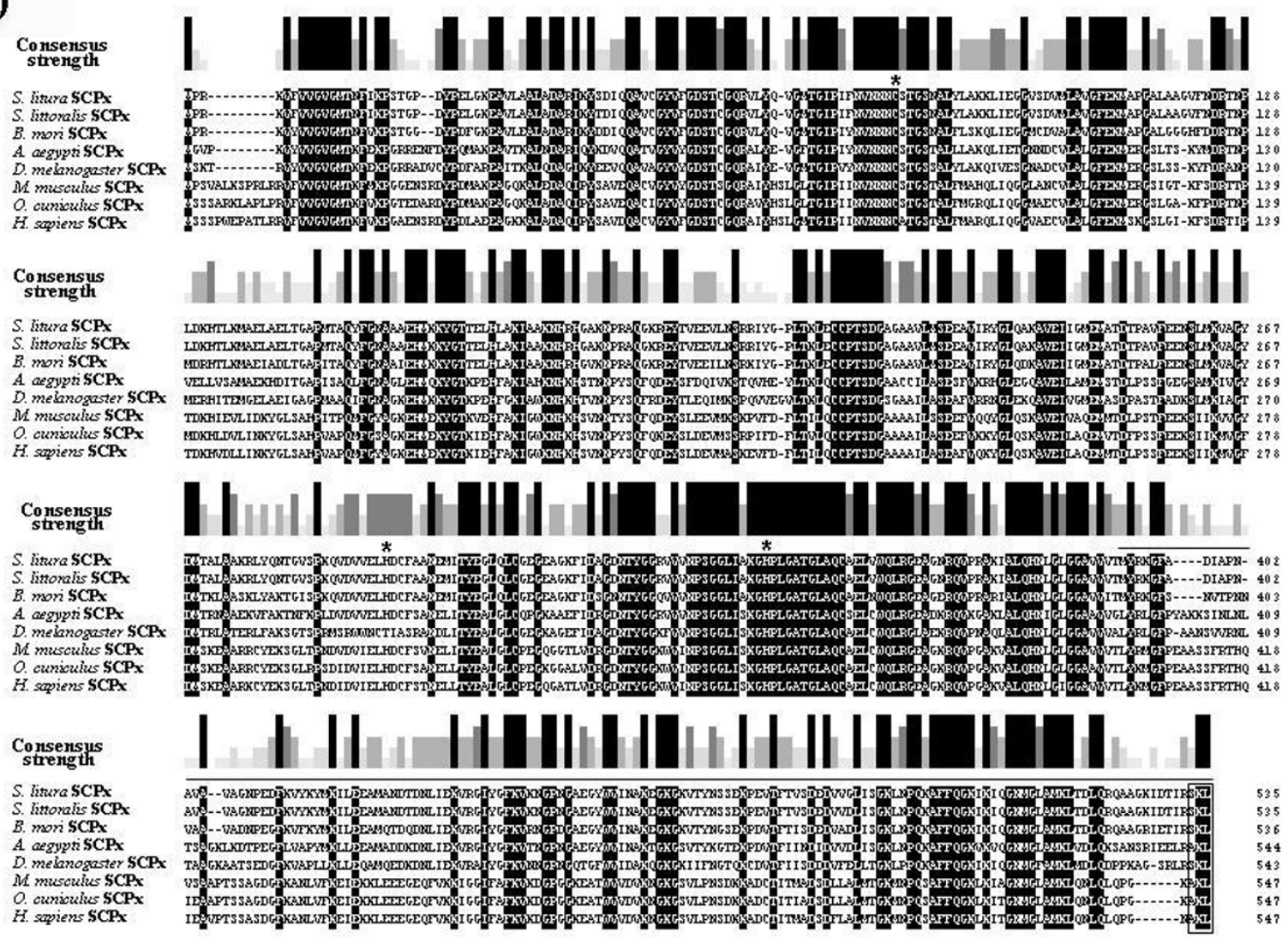

(B)

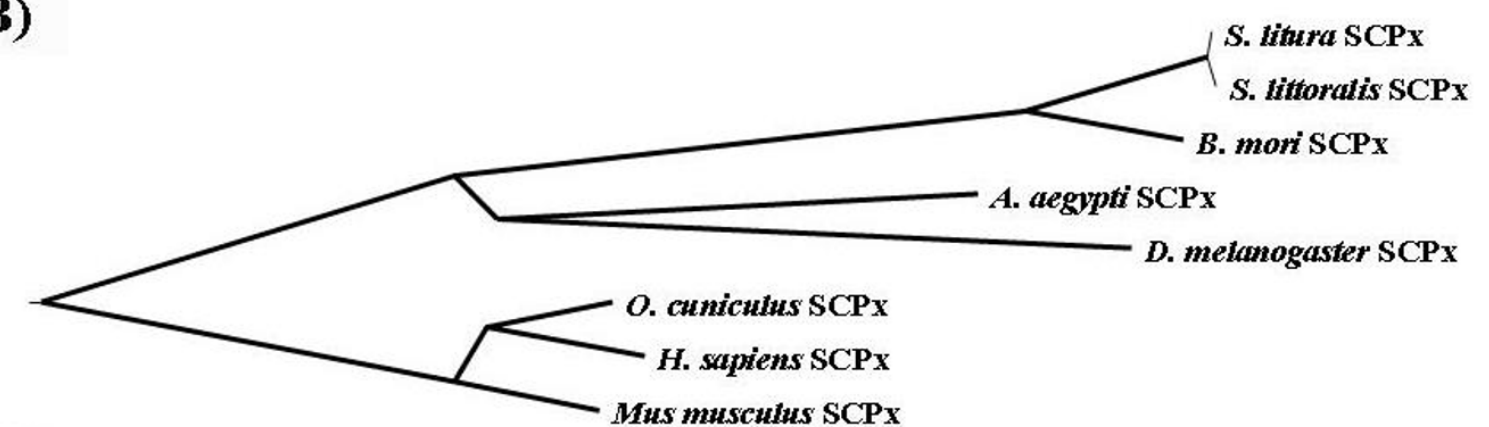

43.2

\begin{tabular}{|lllllllll} 
& & & & & & & & \\
40 & 35 & 30 & 25 & 20 & 15 & 10 & 5 & 0
\end{tabular}

Nucleotide Substitutions (x100)

Figure 3

Alignment and phyologenetic tree analysis of the deduced amino acid sequences of SISCPX and its homologues. (A) Sequence alignment and (B) phyologenetic analysis of SCPx homologues from other species. S. littoralis SCPx (AAT72922), A. aegypti SCPx (AAF537I3), B. mori SCPx (NP_00I037378), D. melanogaster SCPx (NP_5247I5), O. cuniculus SCPx (AF05 1897), H. sapiens SCP-x (P32020) and M. musculus SCPx (AAA40098). The amino acid residues that are identical are indicated by black background. The consensus strength is shown above the sequence alignment panels. The three amino acid residues required for reaction activity of thiolases are indicated by asterisks. The peroxisome targeting sequence (SKL or $\mathrm{AKL}$ ) is boxed. The SCPx-2 region is indicated by a line above the sequence panel. 


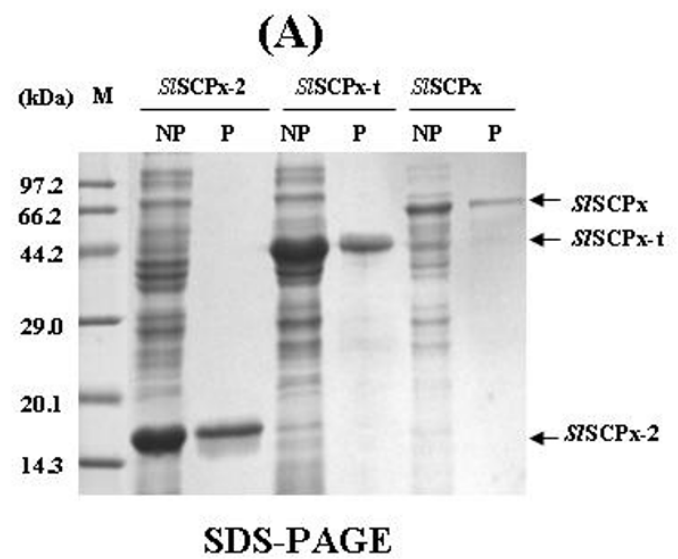

(B)



Western blot
Anti-SCPx
(C)

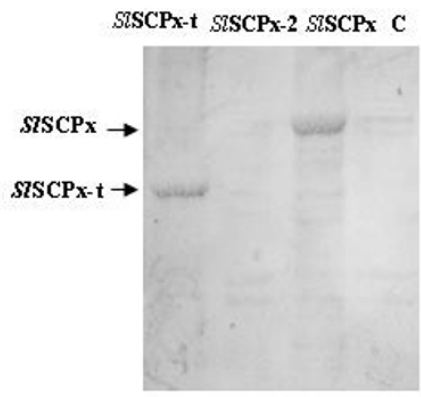

Anti-SCPx-t
(D)

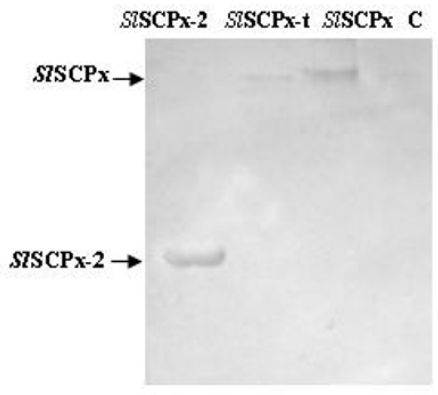

Anti-SCPx-2

\section{Figure 4}

In vitro expression, purification and antibody production of SISCPx, SISCPx-t and SISCPx-2 recombinant proteins in a bacterial expression system. (A) In vitro expression and purification of the recombinant proteins; (B-D) immune reaction of SISCPX, SISCPX-t and SISCPX-2 recombinant proteins. The recombinant proteins were purified using the His-tag affinity column. The protein samples ( $10 \mu \mathrm{g} / \mathrm{lane})$ were analyzed on I5\% SDS-PAGE gel and stained with Commassie Blue R250. On the western blotting analyses (B-D) the proteins were blotted with the corresponding anti-SISCPx antiserium at I:I,500 dilution. C: control; NP: non-purified; P: purified.

instar larvae) than during the larval molting (L6 white head) stage and the larval to pupal transition (green pupae) (Fig. 5A). The expression declined to a lower level after day 2 post pupation. The SISCPx-2 (0.9 kb) mRNA was also detected in the epidermis and fat body when a labelled SISCPX-2 DNA fragment was used as a probe (Fig. $5 \mathrm{~B})$. When a labelled DNA fragment of the SiSCPx-t region was used as a probe, only the SISCPx $(2.8 \mathrm{~kb}$ and $2.0 \mathrm{~kb}$ ) mRNA transcripts were detected (Fig. 5C). These two transcripts were highly expressed during the feeding stage (days 1 to 3 ) of $6^{\text {th }}$ instar larvae, but decreased when the larvae started wandering and entered the prepupal stage (Fig. 5C). These northern blotting analyses indicated that SISCPX was specifically and highly expressed in the midgut during the larval feeding stage, while SlSCPX-2 mRNA was also found in the epidermis and fat body, in addition to the midgut.

Western blotting analysis was performed to examine the levels of these proteins in the different tissues and stages of $6^{\text {th }}$ instar larvae (Fig. 5D-F). The anti-SlSCPx-2 antibody detected a single band of SlSCP-2 protein in the midgut and fat body of 3-day-old $6^{\text {th }}$ instar larvae, but not in the epidermis (Fig. 5D). This was contrast to the northern blotting analysis where the SlSCPx-2 transcript was also detected in the epidermis (Fig. 5A). This is probably because only a very low level of SlSCPX-2 protein translation occurred in the epidermis at this stage. The anti-SlS- 
(A)

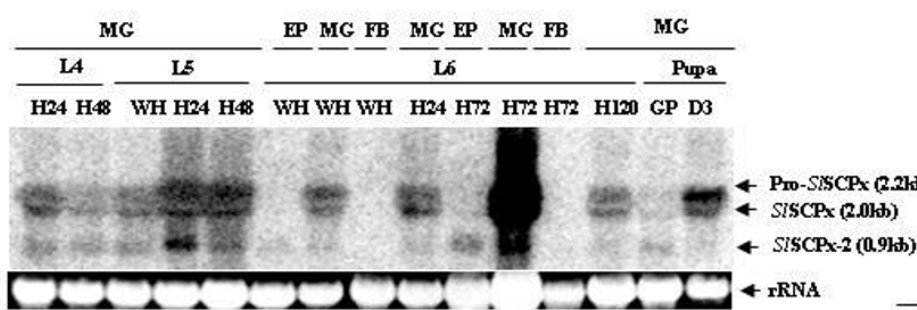

(D)

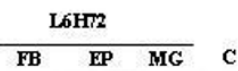

(B)



(C)

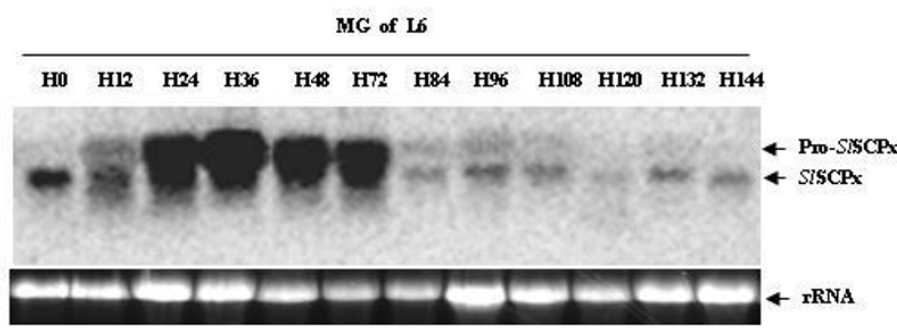

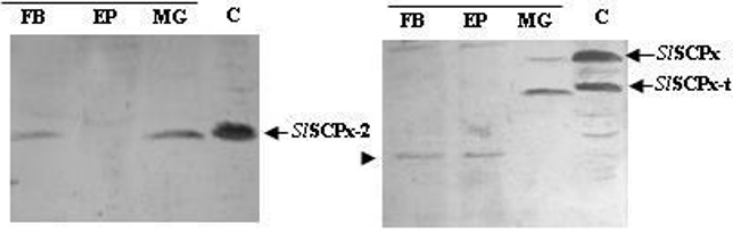

(F)

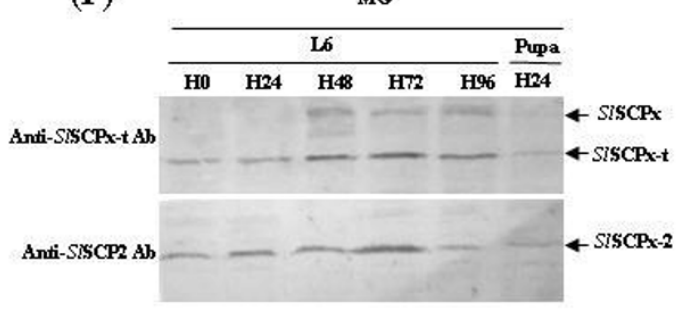

\section{Figure 5}

Northern and western blotting analysis of temporal and spatial expression of the SISCPx gene and protein. Ten microgram aliquots of total RNA from various tissues and stages was used in each of the lanes in the northern blots (A-C). The blots were hybridized with ${ }^{32} \mathrm{P}$-labelled DNA probes of the SISCPx-2 region (A and $\left.\mathrm{B}\right)$ and the SISCPx-t region (C), respectively. In the western blots (D-F), the protein extracts were blotted with anti-SISCPx-2 antibody (D and the lower panel of $F$ ) and anti-SISCPX-t antibody (E and the upper panel of F), respectively. The arrowhead in (E) indicates an unidentified protein present in the fat body and epidermis. C: the recombinant protein extract from bacterial expression system. L: larvae; D: day; $\mathrm{H}$ : hours; WH: white head; MG: midgut; EP: epidermis; FB: fat body; P: pupae. Pro-SISCPx is the putative pre-mutual transcript of the full-length SISCPx mRNA.

CPx-t antibody detected a major $44-\mathrm{kDa}$ protein and a weak 58-kDa protein, which were closely equivalent to the predicted molecular mass of the SlSCPx-t (thiolase domain) and full-length SlSCPx proteins, respectively and as observed for bacterially expressed equivalents (Fig. 5E). No such proteins were detected in the fat body and epidermis, where another small unidentified protein immunologically reacted with the anti-SISCPx-t antibody. These results indicated either that SISCPX was post-translationally and proteolytically cleaved into two smaller proteins SlSCPX-t and SISCPX-2, or that the transcription of the SlSCPx gene was initiated at two different transcription initiation sites, generating a full-length SlSCPx mRNA, which was translated into a full-length protein that was proteolytically cleaved into SlSCPx-t and SlSCPX-2 proteins post translationally, and a SlSCPx-2 mRNA that was translated into a SlSCPX-2 protein. It was also noticed that the relative levels of SISCPX-t and SISCPX-2 proteins were higher than that of SlSCPx protein, suggesting that SISCPx protein was rapidly cleaved into SlSCPx-t and SlSCPx-2 proteins after synthesis. The levels of the three proteins SlSCPX, SlSCPX-t, SlSCPX-2 were higher during the feeding stage (for example, days 1-3 of $6^{\text {th }}$ instar) than non-feeding stages (for example, day 0 of $6^{\text {th }}$ instar larval stage and pupal stage) (Fig. 5F). These results from protein analysis were consistent with the results of northern blotting analyses for mRNA profiles. 
Tissue and cellular localization of SISCPx, SISCPX-t and SISCPx-2 proteins in larvae and in vitro Spli-22 I cells Localization of SlSCPx, SlSCPx-t and SlSCPX-2 proteins in larvae was examined using immunohistochemistry (Fig. 6). When anti-SlSCPx antibody was used as the primary antibody, the protein was detected mainly in the midgut of 2-day-old $6^{\text {th }}$ instar larvae (Fig. 6Ab), although a trace amount of protein was also found in the epidermis and fat body. This result was consistent with the result of the western blotting analysis, in which the protein was mainly present in the midgut (Fig. 5D-F). In addition, the SISCPX, SlSCPX-t and SlSCPX-2 proteins were distributed in the different regions of the midgut epithelium (Fig. 6Ab-d). The SISCPx protein was distributed almost evenly in most of the epithelial cells (Fig. 6Ac), while the SISCPx-t protein was detected mostly in the epithelial cells that were close to the lumen side (Fig. 6Ad) and the SlSCPx-2 protein was localized in the epithelial cells that were close to the basal membrane side of the midgut epithelium (Fig. 6Ae). Subcellular distribution of the proteins was also examined by using two approaches. Firstly, protein extracts were isolated from the cytosol and nuclear fractions, respectively, from the midgut epithelial cells of 3-day-old $6^{\text {th }}$ instar larvae and were analyzed by western blots using anti-SlSCPX-
(A)
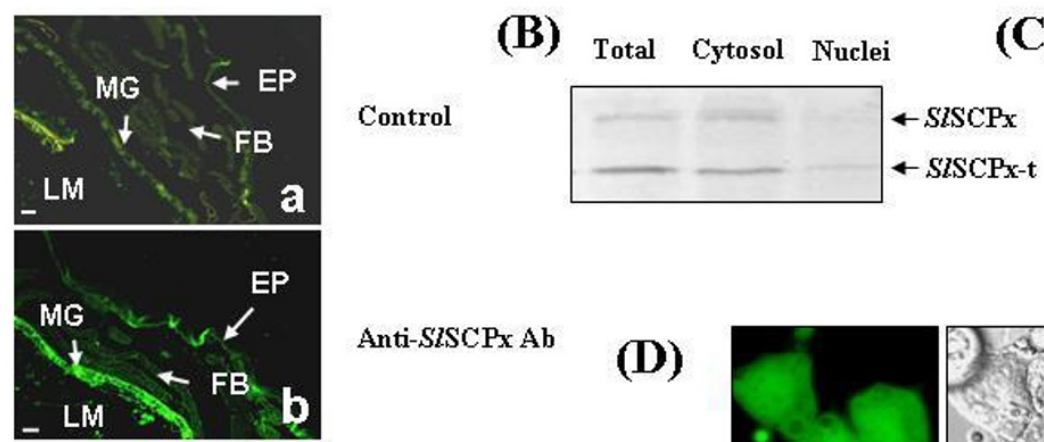

Anti-SISCPx Ab

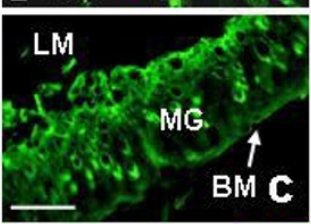

Anti-SlSCPx Ab

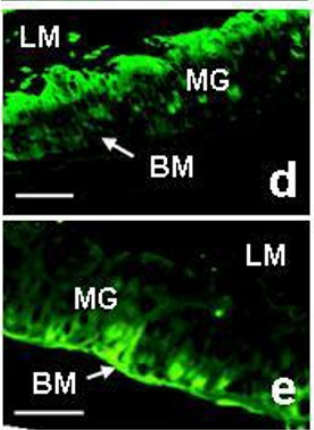

Anti-SISCPx-t Ab

Anti-SISCPx-2 Ab
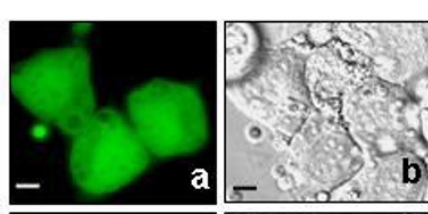

GFP alone
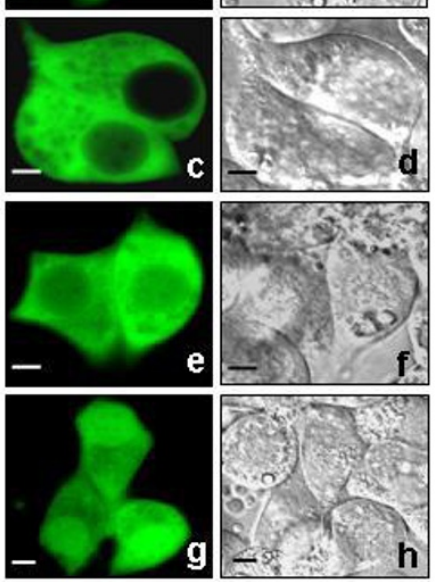

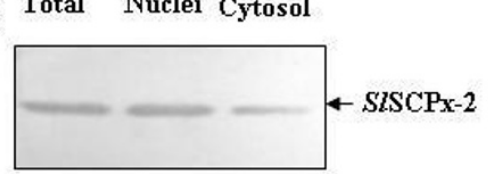

$S I S C P x / G F P$

SlSCPx-t/GFP

SISCPx-2/GFP

\section{Figure 6}

Localization of SISCPx, SISCPx-t and SISCPx-2 proteins. (A) Immunohistochemistry localization of SISCPx, SISCPx-t and SISCPx-2 proteins in the 2-day-old $6^{\text {th }}$ instar larvae of S. litura; (B and C) subcellular localization of the proteins in epithelial cells of the midgutand in the transfected Spli-22I cells (D). Anti-SISCPx, SISCPx-t and SISCPx-2 antibodies were used at a dilution of $1: 200$ in $(A)$. The proteins for western blotting analysis were extracted from the cytoplasm and nuclei of the midgut epithelial cells of 3-day-old old $6^{\text {th }}$ instar larvae. Following electrophoresis of $20 \mu \mathrm{g}$ protein/lane blots were probed by anti-SISCPx$t(B)$ and anti-SISCPx-2 (C) antibodies, respectively. The bands in (B) run at approximately $58 \mathrm{kDa}$ and $44 \mathrm{kDa}$, respectively, and the band in (C) at approximately $16 \mathrm{kDa}$. (D) Spli-22I cells were transfected with pEGFPI (Da and Db), pESISCPx/GFP (Dc and Dd), pESISCPx-t/GFP (De and Df) and pESISCPx-C/GFP (Dg and Dh) plasmid DNAs, respectively. The photographs were taken through fluorescence (Da, Dc, De and Dg) and visible light filters (Db, Dd, Df and Dh) at $24 \mathrm{~h}$ post transfection. MG: midgut; EP: epidermis; FB: fat body; LM: lumen; BM: basal membrane. The scale bars represent $60 \mu \mathrm{m}$ in (A) and I0 $\mu \mathrm{m}$ in (D). 
$\mathrm{t}$ and anti-SlSCPx-2 antibodies (Fig. 6B and 6C). The antiSlSCPx-t antibody detected two protein bands (approximately $58 \mathrm{kDa}$ and $44 \mathrm{kDa}$ ), presumably being SlSCPx and SISCPx-t, respectively, at a higher level in the cytoplasm than in the nuclei of the epithelial cells (Fig. 6B), indicating that these two proteins were mainly present in the cytoplasmic fraction. The anti-SlSCPx-2 antibody detected the protein at a higher level in the nuclei than in the cytosplasm of the midgut epithelial cells (Fig. 6C), suggesting that the SlSCPx-2 protein was primarily in the nuclei. Secondly, the embryogenic cell line, Spli-221, of $S$. litura was transfected with the eukaryotic expression vector pEGFP-1 expressing SlSCPx/GFP, SlSCPx-t/GFP and SlSCPx-2/GFP fusion proteins, respectively (Fig. 6D). At $24 \mathrm{~h}$ post transfection, more than $60 \%$ of the cells expressed green fluorescence, indicating that most of the cells were transfected by the plasmid DNAs. The confocal fluorescence microscopy observation on the transfected cells revealed that the green fluorescence signal in the control cells, which were transfected with the plasmid pEGFP1 expressing GFP alone, was seen in both the cytoplasm and nuclei (Fig. 6Da). In the SISCPx/GFP over-expressing cells the green fluorescence was detected only in the cytosol and almost no signal was found in the nuclei (Fig. 6Dc). In the SlSCPx-t/GFP over-expressing cells, stronger fluorescence signal was found in the cytoplasm than in the nuclei (Fig. 6De). The fluorescence signal of SlSCPx-2/ GFP was also seen in both the cytoplasm and nuclei, but with a higher intensity in the nuclei than in the cytoplasm (Fig. 6Dg). All of these results from the immunohistochemistry of the midgut epithelial tissues (Fig. 6A), western blotting analyses of cytoplasmic and nuclear protein extracts (Fig. 6B and 6C), and transient expression of the GFP-marked proteins in the cultured Spli-221 cells (Fig. 6D), taken together suggest that the SlSCPx and SlSCPx-t proteins are localized predominately in the cytoplasm of the epithelial cells, particularly the cells that are close to the lumen side of the epithelium in the case of SISCPx-t protein, while the SISCPX-2 protein was localized in both the nuclei and the cytoplasm of the epithelial cells that were close to the basal membrane side of the midgut epithelium.

\section{Effect of SISCPx and SISCPx-2 expression on cholesterol uptake in the Spli-22I cell line}

To examine if SlSCPx protein can influence the cholesterol uptake, cholesterol levels in the transfected cells were measured and compared with that in the control cells. The intact SlSCPx coding region and SlSCPx-2 domain region alone were cloned, respectively, into the pEGFP-1 vector replacing the GFP and under the control of the insect baculovirus IE1 promoter. The recombinant plasmids were used to transfect Spli-221 cells to express these recombinant proteins. After overnight culture in sterol-free medium, the medium was replaced with fresh medium containing $0.2 \mathrm{mg}$ cholesterol per $\mathrm{ml}$ of medium. The cells were collected after overnight culture in this sterol medium. Protein expression and cholesterol levels in the cell extracts were analyzed. The anti-SlSCPx antibody detected $58-\mathrm{kDa}$ and $16-\mathrm{kDa}$ bands in the protein extracts from the SlSCPx- and SlSCPx-2-transfected cells, respectively (Fig. 7A), indicating that the recombinant proteins (58 kDa for SlSCPx and $16 \mathrm{kDa}$ for SlSCPx-2) were expressed in the transfected cells. An additional protein band of approximately $50-\mathrm{kDa}$ immunologically crossreacted with the antibody in all of the transfected cells (including the pEGFP-1 control) and needs to be identified. HPLC analysis of cholesterol levels in the transfected cells revealed that the SISCPx and SlSCPx-2 transfected cells contained higher levels of cholesterol than the control cells transfected with the pEGFP-1 vector (Fig. 7B). The effect of SlSCPx-2 appeared to be more significant ( $\mathrm{p}$ $<0.01)$ than SlSCPx $(\mathrm{p}<0.05)$ on the increase of the cholesterol level as compared to the control. This resulted suggests that expression of SISCPx or SISCPx-2 increased cholesterol uptake into the Spli-221 cells from the sterolcontaining medium.

\section{Effects of dsRNA interference of SISCPx transcripts on cholesterol uptake in larvae}

To examine the function of SlSCPx, dsRNA of SlSCPx was synthesized in vitro and injected into the hemolymph of larvae molting from $5^{\text {th }}$ to $6^{\text {th }}$ instar stage. RT-PCR and western blotting analyses indicated that the SISCPx dsRNA efficiently reduced the levels of both the SISCPx and SISCPx-2 transcripts (Fig. 8A) and the three proteins (Fig. 8B) of the target SlSCPx gene between day 1 and 3 post injection. The hemolymph was collected after 24,48 , 72 and $96 \mathrm{~h}$ post injection and cholesterol levels in the hemolymph were examined by using HPLC. The results indicated that SlSCPx-dsRNA-treated larvae had a significant decrease in the hemolymph cholesterol level at day 2 $(\mathrm{p}<0.05)$ and day $3(\mathrm{p}<0.01)$ post injection, as compared to the GFP-dsRNA-treated control larvae (Fig. 8C). Furthermore SISCPx dsRNA interference resulted in a delay in the larval development, for example, from the larval to the pupal transformation by an extension of 2-3 days as compared to the controls (Fig. 8D). All of the control larvae completed the molting process before day 9 post injection, whereas more than $40 \%$ of the SlSCPxdsRNA-treated larvae were still at the last larval stage until day 12 post injection. The SlSCPx-dsRNA-treated larvae were smaller in body size than the control animals (Fig. $8 \mathrm{E})$. The results from the RNAi-treatment suggest that knocking down the transcripts of SlSCPx reduced the level of cholesterol in the hemolymph and retarded the growth and development of the larvae, probably by affecting the synthesis of ecdysteroid and cell membrane formation among other things. 
(A)

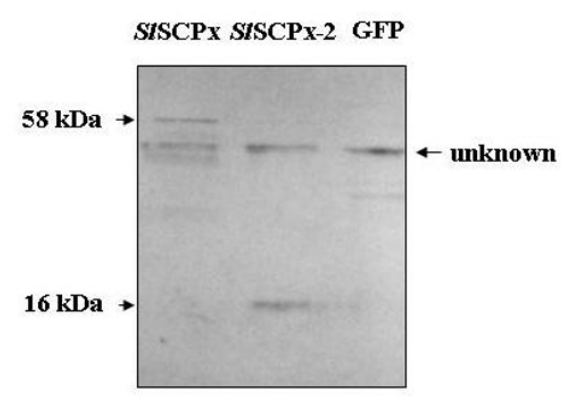

(B)

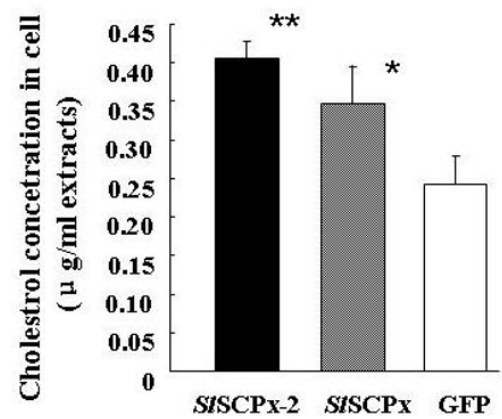

\section{Figure 7}

Effect of SISCP-x and SISCPx-2 protein expression on the absorption of cholesterol in the Spli-22I cells transfected with pESISCPx/GFP and pESISCPx-2/GFP transfection vectors, respectively. (A) Western blotting analysis of the protein extracts from the transfected Spli-22I cells. Proteins were analyzed on a I2\% SDS-PAGE gel and each lane contained $20 \mu \mathrm{g}$ protein. (B) Cholesterol concentrations in the transfected cells were analyzed using HPLC at $36 \mathrm{~h}$ post transfection. The control was the cells transfected with a PEGFP vector expressing only GFP. Three independent replicates were performed for each data point. The concentration of cholesterol in the cells or hemolymph was calculated as $\mu \mathrm{g} / \mathrm{ml}$ of medium or hemolymph.

\section{Discussion}

The SCP-2 gene family has been implicated in the absorption and transport of lipids, fatty acids and cholesterols [1]. Studies have shown that SCP-2 proteins have multiple functions because of their capability to bind with cholesterol, fatty acids and fatty acyl CoA and regulating lipid rafts and signalling processes [28-32]. The human SCPx gene, which is a member of the SCP-2 family, encodes a $58-\mathrm{kDa}$ fusion protein that is post-translationally processed into a $46-\mathrm{kDa}$ thiolase and a $13-\mathrm{kDa}$ SCP-2 protein. Only one single copy of the SCPx/SCP-2 gene is found in the genomes of humans, mice and rats [1]. In C. elegans the homologous gene encodes a $\mathrm{P} 44$ protein, which lacks the SCP-2 domain at the 3 '-terminal region of the protein [18]. In Diptera, such as D. melanogaster and A. aegypti, SCPx gene produces a single transcript encoding a fulllength SCPx, but does not encode SCP-2 mRNA $[19,20]$. Instead, separate genes in the $A$. aegypti genome encode small SCP-2 and SCP-2-like proteins, which do not contain the thiolase domain $[33,34]$. In lepidopteran insects, such as $S$. littoralis [21] and B. mori [22], which is a very close allopatric species of $S$. litura, a single SCPx/SCP-2 gene encodes both SCPx and SCP-2 mRNAs, which suggests that it is generated by alternative splicing into two mRNA isoforms after transcription and no other separate SCP-2 genes for SCP-2 proteins are present in these lepidopteran genomes. In this study, northern blotting analysis detected three transcripts of $2.8 \mathrm{~kb}$ (putative proSlSCPx), $2.0 \mathrm{~kb}$ (SlSCPx) and $0.9 \mathrm{~kb}$ (SlSCPx-2) in the midgut of $S$. litura when a DNA fragment of the SCP-2 coding region (SlSCPx-2) of SlSCPx was used as a probe (Fig. 5A). However, when the SlSCPx-t region of the SlSCPx gene was used as a probe, the $0.9 \mathrm{~kb}$ band was not detected (Fig. 5C). RT-PCR using a pair of primers specific to the 5 -terminus and 3 '-teminus of the full-length SCPx ORF and total RNA isolated from the larval tissues amplified two cDNAs that encoded for the full-length SISCPx mRNA and the SlSCPx-2 domain mRNA, respectively (Fig. 2 ). There are at least three possible explanations for the multiple transcripts of SlSCPx gene: One is that the two amplified mRNA transcripts are the products of the same SlSCPx gene, but result from different transcription initiation sites, as is the case in human SCPx/SCP2 gene [9]. In humans, the SCPx gene generates a 2.8-kb mRNA encoding a fused 58-kDa protein (3-ketoacyl-CoA thiolase plus SCP-2) and a $1.5-\mathrm{kb}$ mRNA encoding only a $15.3-\mathrm{kDa}$ SCP-2 protein [9]. The $58-\mathrm{kDa}$ protein was post-translationally cleaved into $46-\mathrm{kDa}$ thiolase and $15-\mathrm{kDa}$ SCP-2 proteins [1]. The $15-\mathrm{kDa}$ pro-SCP-2 protein is the precursor of the mature 13-kDa SCP-2 and the 20-amino acid peptide at the 5 -terminal end may alter SCP- 2 structure to facilitate peroxisomal targeting $[28,29]$. However, in the present study the promoter sequence of the gene was not determined and the genomic organization of the gene has not been elucidated, therefore we do not know if there was any promoter regulation of the gene to provide two transcripts. A second possibility is that there are other separate genes that encode SCP- 2 mRNA transcripts in the midgut. However, Southern blotting analysis of genomic DNA indicated that only a single band was detected (data 
(A)

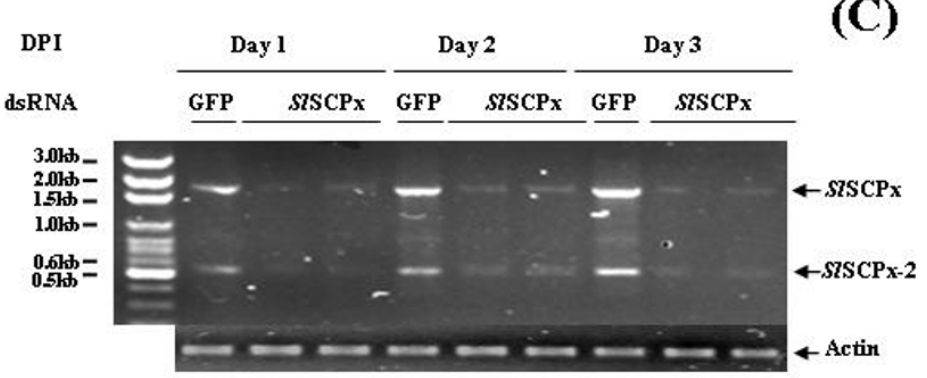

(B)

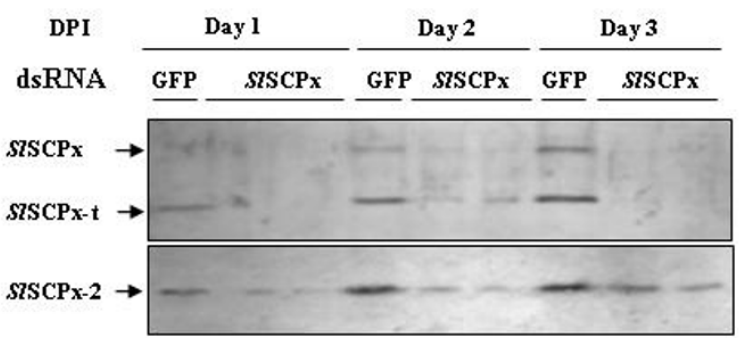

(C)

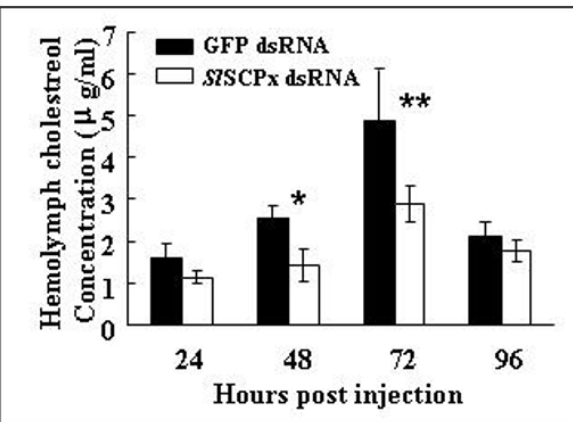

(D)

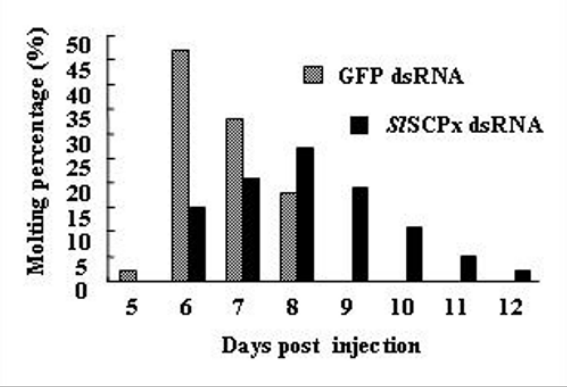

(E)

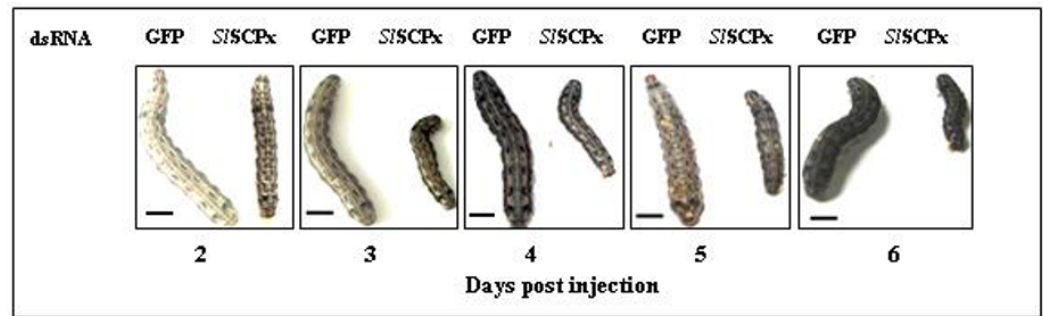

Figure 8

Effects of SISCPx dsRNA interference on the levels of the transcripts and proteins of the SISCPx gene, cholesterol level in the hemolymph and molting and growth of the $6^{\text {th }}$ instar larvae. (A) A total of $4 \mu \mathrm{g}$ of dsRNA per larva was injected into the larvae after ecdysis into the $6^{\text {th }}$ instar stage. Total RNA and proteins were extracted from the midgut of the 30 treated larvae for transcript analysis by RT-PCR and protein analysis by western blotting analysis, respectively. In the RT-PCR analysis, $\alpha$-actin amplification from the same RNA samples as the target gene was used as an internal control. DPI: days post injection. (B) In the western blotting analysis $30 \mu \mathrm{g}$ of proteins was loaded per lane and were probed with anti-SISCPx antibody (upper panel of $B$ ) and anti-SISCPx-2 antibody (lower panel of B), respectively. For the SISCPx treatments, expression of RNA (A) and protein (B) in two independent individual samples are shown. The control was the samples injected with GFP dsRNA (A and B). (C) The hemolymph cholesterol levels in the SISCPx dsRNAi treated insects and the control. Three independent replicates were performed for each data point. The concentration of cholesterol in the cells or hemolymph was calculated as $\mu \mathrm{g} / \mathrm{ml}$ of medium or hemolymph. (D) Pupation incidences in dsRNA-treated larvae. The scale bars represent $8 \mathrm{~mm}$.

not shown), suggesting that only one gene of SlSCPx is present in the genome. Thirdly, perhaps two transcripts were derived from alternative splicing of a full-length transcript (SISCPx) into the two transcripts post transcriptionally, encoding the full-length SlSCPx and SlSCPX-2, respectively, as suggested by the two full-length SISCPx mRNA and SISCPx-2 mRNA amplified PCR products detected (Fig. 2A). Because the primers used would be unable to detect a transcript for the SISCPx-t region only we cannot rule out such a transcript. Nevertheless, northern blotting analyses revealed that no mRNA transcript for SlSCPx-t only, which was expected to be $1.23 \mathrm{~kb}$, was detected when either SISCPx or SISCPx-t DNA fragment was used as a probe. Therefore, the most likely explanation is that the full-length transcript (SISCPx) was alternatively spliced into the two transcripts post 
transcriptionally. Our hypothesis concurs with the demonstration in B. mori, where the BmSCPx/SCP-2 gene also contains thiolase and SCP-2 domains and they are encoded by two separate exons, respectively [22], generating two isoforms of SCPx and SCP-2 mRNA. This is also similar to the cases in mammals [1] but differs from the Diptera, such as D. melanogaster and A. aegypti, in which the SCPx gene generates only SCPx mRNA but not SCP-2 mRNA $[19,20]$. These results and analyses suggest a hypothesis that the S. litura SlSCPx gene produces an mRNA transcript that contains both a SISCPx-t domain for a 3-oxoacyl-CoA thiolase and a SiSCPx-2 domain for a SCP-2 protein, and a SlSCPx-2 mRNA transcript for SlSCP2 protein by splicing (Fig. 2). It is interesting that in the feeding larvae the SISCP-2 mRNA was found not only in the midgut but also in the epidermis and fat body, where no SlSCPx mRNA was detected. This suggests that this alternative transcription of SlSCX-2 can occur in different tissues other than the midgut. However, although there was SlSCPX-2 transcripts detected in the epidermis of feeding larvae, for example at day 3 of $6^{\text {th }}$ instar stage (Fig. 5A), but no immunoreactive protein of SlSCPx-2 was detected by western blotting analysis. This probably indicates that only a low level of SlSCPX-2 protein translation occurred in the epidermis at this stage, although the SlSCPx-2 transcripts were present. The regulatory mechanism for transcription and translation of the SISCPx-2 gene is worth to be further examined.

In addition to the regulation of gene expression at the transcription level, the regulation of the protein production can take place at the post-translational level. The antiSlSCPx-t antibody detected two protein products of 58 $\mathrm{kDa}$ (for full-length SlSCPx) and $44 \mathrm{kDa}$ (for SlSCPx-t) in the midgut (Fig. 5E and 5F), while the anti-SlSCPx-2 antibody detected a product of $16 \mathrm{kDa}$ (for SlSCPx-2) in the midgut and fat body (Fig. 5D and 5F). These data suggest that the SISCPx gene is transcribed into a full-length mRNA that is translated into a polypeptide, which is proteolytically cleaved into two peptides: 3-oxoacyl-CoA thiolase (SlSCPX-t) and SlSCPx-2, through a post translational activity. It was also observed that the SISCPX protein was cleaved into thiolase and SCP-2 at a much higher level (Fig. 5F) than the vertebrate SCPx which is processed into the thiolase domain and SCP-2 domain proteins post-translationally at about 50\% level [1].

In mouse, knocking out the SCPx/SCP-2 gene, which affect both SCPx and SCP-2 expression, showed that this gene is required for peroxisomal $\beta$-oxidation of methylbranched fatty acyl-CoAs and bile acid precursors [13]. In human, SCPx mutation, which only affected SCPx but not SCP-2 expression, resulted in an accumulation of the branched-chain fatty acid, pristanic acid, and excretion of abnormal bile alcohol glucuronides in urine [32]. These results indicate that the SCPX gene plays critical roles in the breakdown of branched-chain fatty acids and bile acid metabolism. Some other studies have revealed that SCPx/ SCP-2 and SCP-2 proteins are involved in cholesterol binding and transport [14,34-36]. Three lines of evidence show that both of the SlSCPx and SlSCPX-2 proteins play critical roles in cholesterol absorption in S. litura. Firstly, northern and western blotting analyses showed that the SlSCPx mRNA was specifically present at higher levels in the midgut of the feeding $6^{\text {th }}$ larvae (Fig. 5A and 5C), while the SISCPX-2 mRNA was predominately present in the midgut, but also in both the fat body and epidermis (Fig. 5B). The expression of SlSCPx mRNA was much higher during the feeding stages than the non-feeding stages, indicating that these proteins may be necessary for absorption and transport of nutrients such as cholesterol, during larval feeding stages. Secondly, the over-expression of SISCPx and SlSCPx-2 proteins increased cholesterol uptake into the in vitro cultured S. litura Spli-221 cells from the culture medium (Fig. 7). Thirdly, when the SISCPx mRNA was suppressed by SISCPx dsRNA interference the hemolymph cholesterol level in the treated larvae decreased and the development of the insect was delayed (Fig. 8). Collectively these results suggest that SlSCPx and SlSCPX-2 may play critical roles in cholesterol absorption in S. litura.

This study provides evidence for the association or links among SCPx gene, cholesterol accumulation and development in lepidopteran insects. Insects must take up cholesterol from their diet and accumulate the cholesterol in their bodies during the feeding stages for their growth and development because they lack key cholesterol biosynthesis enzymes, such as squalene monooxygenase, and lanosterol synthase $[3,37]$. The midgut and possibly the foregut are the sites of cholesterol absorption [38-40] and the midgut is a major site for cholesterol absorption into the hemolymph [39]. It has also been demonstrated that SCP2 protein is necessary for cholesterol uptake in $A$. aegypti [24]. Knocking down AeSCP2 transcript expression in $A$. aegypti resulted in a reduction of cholesterol accumulation in pupae and a high mortality in developing adults and reduced egg viability [24]. It is well known that cholesterol is a precursor of 20-hydroxyecdysone (20E) and is a structural component of cell membranes [3]. When cholesterol is absent from the diet, the Heliothis zea neonate larvae fail to molt into $2^{\text {nd }}$ instar stage or suffer a delay in larval growth and pupation $[41,42]$. The present study demonstrates an association or link between SCPx gene, cholesterol accumulation and larval development. Like AeSCP2 in A. aegypti [24], interference in expression of the SlSCPx transcript in the larvae that just molted into $6^{\text {th }}$ instar stage resulted in a decrease in the cholesterol accumulation in the hemolymph and a delay in the larval development and pupation (Fig. 8C-E). Since cholesterol 
is a precursor of $20 \mathrm{E}$ and is a structural component of cell membranes [3], inhibition of uptake and transport of cholesterol by SlSCPx RNAi would impacts adversely on the biosynthesis of 20E that initiates and regulates molting and metamorphosis, resulting in a delay in larval development and pupation. However, in this study only hemoplymph cholesterol levels were examined and the cholesterol levels in the fat body and midgut as well as other tissues were not determined. Whether or not the changes in the hemoplymph cholesterol levels are due to the release of cholesterol from other tissues such as the fat body need to be examined. Direct evidence for the 20E level alteration by the SISCPx suppression and cholesterol accumulation will help define the relationships among these three processes. Another possible mechanism for the inhibition of larval growth and metamorphosis by SlSCPx suppression is that these proteins may be involved in fatty acid metabolism $[28,29]$ and signal transduction [31] and may have to be examined. Since SlSCPx dsRNA covering the SlSCPX-t and SlSCPx-2 domains (Fig. 2) were used to inhibit the SlSCPx transcription and it appeared that both of SlSCPx and SlSCPx-2 transcripts were efficiently knocked down (Fig. 8A and 8B), and it is not clear which protein, if either plays a more critical role in cholesterol accumulation, ecdysteroid synthesis and larvalpupal transformation. We have laid the groundwork for further studies to critically examine the different possibilities.

In vertebrates, although amino acid sequences of the $C$ terminal region (SCP-2 domain) of SCPx and other SCP2 proteins are identical and have a peroxisomal localization signal sequence (AKL or SKL), SCPx locates exclusively in peroxisomes, while SCP-2 is found in both peroxisomes and cytosol [1]. In A. aegypti, AeSCPx is mostly restricted in the peroxisomes, whereas AeSCP2 encoded by another independent AeSCP2 gene was detected mostly in the cytosol [25]. A recent study indicates that the human SCPx protein undergoes post-translational processing on the peroxisomal surface, releasing a short $C$-terminal product (SCP-2) that acts as a transcription factor [14]. It has been reported that SCPx/SCP-2 is regulated through the Forkhead transcription factor FOXO3a and SCP-2 is speculated to protect fatty acids from peroxidation [43]. The preliminary results of the present study indicate that SISCPx, SlSCPX-t and SISCPx-2 proteins were distinct in their subcellular distribution. In the transfected Spli-221 cells, SlSCPx and SlSCPx-t proteins were present mostly in the cytoplasm (Fig. 6B, Dc and 6De), while SISCPx-2 was localized in both the nuclei and cytoplasm, with a slightly higher level in the nuclei than in the cytoplasm (Fig. $6 \mathrm{C}$ and $6 \mathrm{Dg}$ ). But it remains unclear whether or not SISCPx-2 in nuclei acts as a transcription factor. Interestingly, it was found that the SlSCPx, SlSCPx-t and SlSCPX-2 proteins had different distributions in the midgut epithelium of the feeding larvae (Fig. 6Ab-d). SlSCPx protein (or SlSCPx-t plus SlSCPx2 proteins) was detected by the anti-SlSCPx antibody, which is expected to immunologically react with both of SlSCPx-t and SlSCPx-2 proteins, throughout the epithelial cells (Fig. 6Ac), while the SlSCPx-t protein detected by the specific anti-SlSCPx-t antibody was distributed predominately in the epithelial cells that were close to the lumen side (Fig. 6Ad) and the SlSCPX-2 protein detected by the specific anti-SlSCPx-2 antibody was localized in the cells that were close to the basal membrane side of the midgut epithelium (Fig. 6Ae). These observations may indicate that SISCPx-t and SISCPx-2 proteins play different roles in cholesterol uptake and transport in the midgut of S. litura. In the in vitro transfection experiments using Spli-221 cells, the SlSCPx/GFP fusion proteins contained a GFP peptide. It is not clear if this extra peptide can interfere with the accurate localization, although many reports in the literature indicate that this technique has been used to determine the localization of target genes. Higher resolution is critical to unambiguously establish the sub-cellular localization which should be done in subsequent study. Having established the characterization of the gene and the broad functional analyses we are now in a position to unravel the mechanism behind our observation.

\section{Conclusion}

Cholesterol is required for cell membranes and ecdysteroid biosynthesis in insects. Ecdysteroids regulate growth, development and reproduction in insects. However, insects cannot synthesize cholesterol through de novo biosynthesis and therefore insects must obtain cholesterol or sterols from their diet to fulfill the requirements for their normal growth, development and reproduction. In the present study, by analyzing the gene expression patterns, protein localization, protein over-expression and transcript interference we demonstrated that the SlSCPx gene was expressed predominately in the midgut of larvae at the feeding stages and was involved in cholesterol uptake and normal development in S. litura. Interference of this gene resulted in a decrease in cholesterol uptake, which may result in inhibition of ecdysteroid biosynthesis and consequently a delay in the larval-pupal metamorphosis. Besides understanding the mechanism of cholesterol uptake this study might provide a potential molecular target for insect pest management.

\section{Methods}

\section{Experimental insects and cells}

Spodoptera litura Fabricius (Lepidoptera: Noctuidae) and Spli-221 cell line were from The Entomology Institute of SUN YAT-SEN University, Guangzhou, China. Larvae were reared an artificial diet at $26^{\circ} \mathrm{C}$ in $70-80 \%$ humidity and a photoperiod of $12 \mathrm{~h}$ light and $12 \mathrm{~h}$ dark until they reached the pupal stage or became adult moths. The arti- 
ficial diet used for rearing the insect contained $100 \mathrm{~g}$ soybean powder, $80 \mathrm{~g}$ wheat bran, $26 \mathrm{~g}$ yeast, $8 \mathrm{~g}$ casein, $8 \mathrm{~g}$ Vitamin C, $1 \mathrm{~g}$ choline chloride, $2 \mathrm{~g}$ sorbate, $0.2 \mathrm{~g}$ cholesterol, $0.2 \mathrm{~g}$ inositol, $26 \mathrm{~g}$ agar and $2 \mathrm{ml}$ formaldehyde in one liter. The Spli-221 cell line was cultured at $28^{\circ} \mathrm{C}$ in Grace's insect medium (Invirogen Co., Guagnzhou, Guangdong, China) containing 10\% fetal bovine serum. Cells were passaged every 4 days using a 1:4 dilution of cells.

\section{Chemicals and materials}

DNA restriction enzymes, T4 ligase, Taq RNA polymerase and Random Primer Labelling Kit were purchased from TAKALA BIO Inc (Otsu, Shiga, Japan). Sheep anti-rabbit IgG-SABC-FITC (Strept Avidin-Biotin Complex-fluorescein isothiocyanate) and cholesterol (chromatographic grade) were purchased from Sigma-Aldrich Co. (Guangzhou, Guangdong, China). Trizol-reagent for RNA extraction, lipofectin and Grace's insect medium were purchased from Invitrogen Co. (Guangzhou, Guangdong, China). The steroid-free medium was made according to the description by Lan et al. [44]. MEGAscrip RNAi Kit (Silencer $^{\mathrm{TM}}$ ) for double strands RNA synthesis was purchased from Ambion (Austin, USA). Gel DNA Extraction Kit and Plasmid DNA Preparation Kit were purchased from Qiagen (Pudong, Shanghai, China). Acetonitrile, isopropanol and methanol were chromatographic grade and purchased from Shanghai Biotechnology Inc. of China. Northern blotting membranes (Hybond-XL) and western blotting membranes (Hybond-C) were purchased from Amersham Bioscience Inc. (Piscataway, NJ, USA). His Bind Columns for His-tag protein purification was purchased from EMD Chemicals Inc. (Darmstadt, Germany). pEGFP-1 plasmid DNA was from Clontech Laboratories Inc. (Mountain View, CA, USA). The pPROEXTM HTa expression vector was from Life Technologies Inc. (Gaithersburg, MD, USA). Bradford Protein Assay Kit was purchased from Bio-Rad Laboratories (Hercules, USA).

\section{Sequence analysis}

Annotation was performed using the Alignment Search tools in the National Center for Biotechnology Information BLAST search services [45]. Comparison, alignment and phyologenetic tree analysis of multiple sequences were conducted using CLUSTAL W in MegAlign 5.01 [46] of DNASTAR (DNASTAR, Inc., Madison, WI) at a Gap Penalty of 10 and a Gap Length Penalty of 0.2.

\section{RNA isolation and northern blot analysis}

Total RNA was isolated from larval tissues using Trizolreagent (Invitrogen, Guangzhou, Guangdong, China). The fat body, midgut and epidermis were dissected from the larvae of $4^{\text {th }}$ to $6^{\text {th }}$ instar stages and pupae and immediately frozen in liquid nitrogen, and then stored at $-80^{\circ} \mathrm{C}$ until RNA isolation. Total RNA $(10 \mu \mathrm{g})$ per sample was separated on $1.0 \%$ formaldehyde agarose gels and transferred onto nylon membranes. SlSCPx cDNA was labelled with ${ }^{32} \mathrm{P}$-dCTP using the Random Primer DNA Labelling Kit (TAKALA BIO. Inc., Otsu, Shiga, Japan) and used as probes for northern blot analysis. Pre-hybridization, hybridization and post-hybridization washes were carried out according to Beliveau et al. [47]. Membranes were scanned and photographs were taken in Typhoon TRIO Variable Mode Imager (Typhoon 9400, GE Healthcare Life Sciences, USA).

\section{In vitro expression and purification of SISCPx, SISCPx-t and SISCPX-2 proteins}

For recombinant protein expression in bacterial, the open reading frames (ORFs) of the SlSCPx, SlSCPx-t and SlSCPx-2 cDNAs were amplified by PCR and inserted into the pPROEXTM HTa expression vector (Life Technologies, Burlington, Canada) with $6 \times$ His tag on the C-terminal ends of the target sequences. E. coli cells (DH-5 $\alpha$ ) were transformed with the recombinant plasmid DNAs (pPROEXTM HTa-SlSCPx, pPROEXTM HTa-SlSCPx-t and pPROEXTM HTa-SlSCPX-2). Expression of the His-tagged SlSCPx, SlSCPx-t and SlSCPx-2 fusion proteins was induced by adding IPTG (isopropyl- $\beta$-D-Thiogalactopyranoside) at a final concentration of $1 \mathrm{mM}$. The recombinant proteins were purified using His-tag affinity columns (EMD Biosciences, Darmstadt, Germany). Protein concentrations were determined using Bradford Protein Assay Kit (Bio-Rad, Hercules, USA).

Production of SISCP-x, SISCPx-t and SISCP x-2 antibodies The purified recombinant SlSCPx, SlSCPx-t and SlSCPx-2 proteins were separated on SDS-PAGE gels and stained with Coomassie Blue R-250 and the target bands were excised. The proteins were mixed with Freund's adjuvant and injected into New Zealand White rabbits. Antisera were collected after three booster injections, each with $500 \mu \mathrm{g}$ of the recombinant proteins. Pre-immune serum collected from the same rabbit prior to immunization was used as a control.

\section{SDS-PAGE and western blotting analysis}

Insect tissues were homogenized in lysis buffer $(0.25 \mathrm{M}$ Tris-HCl, pH 8.0, 0.2\% Triton X-100, 1 mM dithioerythritol, $5 \mathrm{mM}$ EDTA, $10 \mathrm{mM} \beta$-mercaptoethanol, $1 \mathrm{mM}$ phenylmethylsulphonyl fluoride, protease inhibitor cocktail), and centrifuged at $12,000 \times \mathrm{g}$ at $4^{\circ} \mathrm{C}$ for $15 \mathrm{~min}$. Supernatants containing soluble proteins were stored at $80^{\circ} \mathrm{C}$. Protein samples were denatured at $100^{\circ} \mathrm{C}$ for $5 \mathrm{~min}$ in an equal volume of $2 \times$ protein loading buffer $(0.1 \mathrm{M}$ Tris buffer, $\mathrm{pH} 6.8,4 \%$ SDS, $0.2 \% \beta$-mercaptoethanol, $40 \%$ glycerol, and $0.002 \%$ bromophenol blue). Protein concentrations were determined using Bradford Protein Assay Kit (Bio-Rad, Hercules, USA). SDS-PAGE was performed in $12 \%-15 \%$ acrylamide gels in tris-glycine-SDS 
buffer (10 mM Tris, $50 \mathrm{mM}$ glycine, 0.1\% SDS, pH 8.0). The gel was stained with Coomassie Blue R-250. The molecular mass of the proteins was calculated using the GeneTools program Tiangen (Tiangen Biotech, Beijing, China). For western blotting analysis, proteins were transferred from the acrylamide gels to nitrocellulose membranes. The membranes were blocked with 3\% BSA in 1× PBS buffer for $2 \mathrm{~h}$ at room temperature, and then incubated with the SISCPX, SISCPX-t and SISCPx-2 antibodies $(1: 1,000)$ at room temperature for $1 \mathrm{~h}$. Goat anti-rabbit IgG (Dingguo Biotechnology, Beijing, China) conjugated with alkaline phosphatase was used as the secondary antibody at a dilution of 1:2,000. Nitroblue tetrazolium and 5-bromo-4-chloro-3-indolyl phosphate was used as substrates for color development.

\section{Immunohistochemistry}

Immunohistochemistry localization of SlSCPx, SiSCPx-t and SISCPX-2 were performed as described by Feng et al. [48]. Whole larvae at the selected stages were fixed with $4 \%$ formaldehyde in $1 \times$ PBS buffer for $24 \mathrm{~h}$ at $4^{\circ} \mathrm{C}$ and embedded in paraffin. Eight-micrometer thick sections were made for immunostaining. The sections were stained first with the primary antibody at a dilution of 1:200 for 1 h. The secondary antibodies, sheep anti-rabbit IgG conjugated with SABC-FITC (Strept Avidin-Biotin Complex-fluorescein isothiocyanate) (Sigma, Guangzhou, China), were used according to the manufacturer's protocol at a dilution of $1: 100$. The sections were counter-stained with 4', 6-diamidine-2'-phenylindole dihydrochloride (DAPI) for $30 \mathrm{~min}$ and examined under a fluorescence microscope (DMI4000B). The photographs were taken as double exposures using fluorescein and DAPI filters.

\section{Preparation of cytoplasmic and nuclear proteins}

Cytoplasmic extracts were prepared as described by Ko and Puglielli [14] with some modifications. Midgut tissues were homogenized in homogenization buffer containing $25 \mathrm{mM}$ Tris- $\mathrm{HCl}$, pH 7.4, 0.5 mM EDTA, $0.5 \mathrm{mM}$ EGTA and a protease inhibitor mixture. The homogenates were centrifuged first at $500 \times \mathrm{g}$ for $5 \mathrm{~min}$. The supernatant were collected and centrifuged at $14,000 \times \mathrm{g}$ for $15 \mathrm{~min}$ and the supernatants containing cytoplasmic proteins were collected.

For nuclear extraction, midgut tissues were suspended in 3 volumes of lysis buffer (20 mM Hepes, pH 7.9, $10 \mathrm{mM}$ $\mathrm{KCl}, 1 \mathrm{mM}$ EDTA, pH 8.0, 10\% glycerol and 10\% protease inhibitor mixture), followed by incubation on ice for 30 min. The resultant supernatants were gently agitated by gently pipetting in and out; the lysates were then centrifuged at $14,000 \mathrm{~g}$ for $30 \mathrm{~min}$ at $4^{\circ} \mathrm{C}$ to obtain nuclear pellets. Nuclear pellets were washed twice with cell lysis buffer (lacking protease inhibitor mixture) and then resuspended in 2 volumes of nuclear extract buffer $(20 \mathrm{mM}$
HEPES, pH 7.9, $10 \mathrm{mM} \mathrm{KCl,} 1$ mM EDTA, pH 8.0, 420 $\mathrm{mM} \mathrm{NaCl}, 20 \%$ glycerol, and $10 \%$ protease inhibitor mixture). The nuclear proteins were extracted by incubation at $4^{\circ} \mathrm{C}$ for $30 \mathrm{~min}$ with gentle agitation, followed by centrifugation at $14,000 \mathrm{~g}$ at $4^{\circ} \mathrm{C}$ for $30 \mathrm{~min}$. The resultant supernatant fraction was used as a nuclear extract.

\section{Expression of SISCPx/GFP, SISCPx-t/GFP and SISCPx-2I GFP fusion proteins in Spli-22 I cell line}

To examine the intracellular location of the SISCPx, SlSCPx-t and SlSCPx-2 proteins in Spli-221 cells, SCP/GFP fusion constructs (SlSCPx/GFP, SlSCPx-t/GFP and SlSCPx2/GFP) were made with the transfection vector pEGFP-1 (Clontech Laboratories Inc., Mountain View, CA, USA) with the GFP fragment at the $C$-terminal end of the fusion proteins. Spli-221 cells were seeded at $2 \times 10^{5}$ cells $/ \mathrm{ml}$ in $2 \mathrm{ml}$ of Grace's medium in 6-well plates. After overnight incubation, the medium was removed and the cells were washed once with $2 \mathrm{ml}$ of the transfection medium without serum and antibiotics. One milliliter of the transfection medium containing $4 \mu \mathrm{g} / \mathrm{ml}$ transfection vectors and $20 \mu \mathrm{g} / \mathrm{ml}$ lipofectin (Invitrogen Co., Guangzhou, Guangdong, China) was added to the cell cultures. The cells were incubated in the transfection medium for $8 \mathrm{~h}$ and then the transfection medium was replaced with $2 \mathrm{ml}$ of fresh Grace's insect medium containing 10\% fetal bovine serum (Invitrogen Co., Guangzhou, Guangdong, China) and incubated at $28^{\circ} \mathrm{C}$. After $24 \mathrm{~h}$ culture, the transfected cells were observed for green fluorescence signals and photographed by laser confocal microscope.

\section{Expression of SISCPx, and SISCPx-2 in Spli-22 I cell line}

To examine if SlSCPx and SlSCPx-2 proteins can influence the cholesterol uptake, the intact SISCPx coding region and SlSCPX-2 domain region alone were cloned, respectively, into the pEGFP-1 vector replacing the GFP and under the control of the IE1 promoter. The cholesterol level in the transfected cells was measured and compared with the level in the control cells. Spli-221 cells were seeded at $2 \times 10^{5}$ cells/ml in $2 \mathrm{ml}$ of Grace's medium in 35 $\times 10 \mathrm{~mm}$ culture dishes. After overnight incubation, the medium was removed and the cells were washed once with $2 \mathrm{ml}$ of the transfection medium without serum and antibiotics. One milliliter of the transfection medium containing $4 \mu \mathrm{g} / \mathrm{ml}$ SlSCPx and SlSCPX-2 expression vectors and $20 \mu \mathrm{g} / \mathrm{ml}$ lipofectin was added into the cell cultures. The cells were incubated in the transfection medium for $8 \mathrm{~h}$ and then the transfection medium was replaced with $2 \mathrm{ml}$ of fresh steroid-free medium containing $10 \%$ fetal bovine serum and incubated at $28^{\circ} \mathrm{C}$. After overnight culture in the steroid-free medium, the medium was replaced with the same medium but containing $0.2 \mathrm{mg}$ cholesterol $/ \mathrm{ml}$ and the cells were cultured for an additional $12 \mathrm{~h}(25,44)$. The cells were washed twice with 2 ml cold $1 \times$ PBS and the total cellular lipids were extracted 
as described below according to Moncecchi et al.[36] for protein and cholesterol analysis.

\section{Cholesterol analysis by high performance liquid chromatography (HPLC)}

Extraction of lipids and sterols from the cell line were conducted as described below. At the indicated time intervals, medium was removed quickly, the cells were washed twice with $1 \times$ PBS, and frozen in liquid $\mathrm{N}_{2}$. The lipids were extracted by adding a mixture of chloroform: methanol 2:1 (v/v) to the collected cells. The samples were mixed well by inverting the tube several times, and then centrifuged at $12,000 \mathrm{~g}$ for $20 \mathrm{~min}$ at $4{ }^{\circ} \mathrm{C}$. The supernatant was collected and a mixture of chloroform:methanol 2:1 (v/v) was added to the pellet to extract the lipids. This step was repeated three times. The supernatants were collected, pooled and evaporated to dryness under a stream of nitrogen. The pellet was dissolved in $200 \mu \mathrm{l}$ methanol and the proteins were filtered through a filter membrane $(0.45$ $\mu \mathrm{m})$ and then stored at $-70^{\circ} \mathrm{C}$ until use. Cholesterol concentrations were determined by HPLC using a ZORBAX XDB C-18 column, $4.65 \mu \mathrm{m} \times 250 \mathrm{~mm}$. under the following conditions: mobile phase:isopropyl alcohol:acetonitrile 4:1 (v/v); flow rate: $1.2 \mathrm{ml} / \mathrm{min}$; wavelength: 208 $\mathrm{nm}$; injection volume: $20 \mu \mathrm{l}$; column temperature: $22^{\circ} \mathrm{C}$.

For hemolymph cholesterol extraction and determination, the process was the same as for the cells, except that the washing step using PBS was skipped. The hemolymph was collected from three larvae for each time point of the treatments and control. Three independent replicates were utilized for each data point. The significance analysis of the differences between the treatments and the control were performed using ANOVA followed by Duncan's Multiple Comparison Test. The data represent mean $\pm S D, n=$ 3. Asterisks "**" and "*" indicate significance at $\mathrm{p}<0.01$ and $p<0.05$ levels, respectively. The concentration of cholesterol in the cells or hemolymph was calculated as $\mu \mathrm{g} / \mathrm{ml}$ of medium or hemolymph.

\section{Double stranded RNA synthesis and RNA interference}

High quality dsRNA was generated using a MEGAscript RNAi Kit (Silencer ${ }^{\mathrm{TM}}$, Ambion, Austin, USA) according the manufacturer's instructions. A twenty base T7 promoter sequence was added to the sense and antisense target sequences: the sense 5'-TAATACGACTCACTATAGGGCTGCTGTGTTTGAGGAGAA-3', the antisense 5'TAATACGACTCACTATAGGGACAAACTAGTACCAGTTTACAA-3' (The underlined bases represent T7 promoter sequence). The quantity of SlSCPx dsRNA was determined by NanoDrop Spectrophotometer measurement at 260 $\mathrm{nm}$ and by agarose gel analysis. The dsRNA was dissolved in elution buffer (10 mM Tris- $\mathrm{HCl}, \mathrm{pH} 7,10 \mathrm{mM}$ EDTA) and used for injection. Double stranded RNA of green flu- orescence protein (GFP) was made using the same method and used as negative control.

Larvae that had just molted into the $6^{\text {th }}$ instar stage displaying a white head capsule were used for dsRNA injection. The larvae were anesthetized on ice for $5 \mathrm{~min}$ prior to microinjection. Four micrograms per larva of dsRNA were injected into the larvae at the intersegment behind the second abdominal segment using a microinjector. Backflow of the body fluid was avoided by sealing with Vaseline and the larvae that lost too much body fluid were discarded. Sixty larvae in each of the three replicates were injected for each of the treatment groups. The larvae were then returned to the artificial diet and reared at $26^{\circ} \mathrm{C}$ until they became adults or were sacrificed for sample collection for RNA, protein and cholesterol analysis. The midgut and hemolymph were collected from 30 individual larvae for RNA and protein analysis and for cholesterol analysis, respectively. Each of the midgut was cut into two equal portions, one for RNA extraction and the other for protein extraction. The remaining 30 animals were then reared for development observation. For cholesterol analysis, the data were represented as mean \pm standard deviation and each data point was generated from the hemolymph from three larvae in each of the three replicates.

\section{Authors' contributions}

XRG performed gene cloning and characterization, in vitro protein expression, northern and western blotting analyses, immuohistochemistry, cholesterol HPLC analysis and RNAi analysis. SCZ and LL coordinated the project and assisted in protein expression, immunohistochemistry and cell culture. QLF and XRG designed the experiments and wrote the paper. QLF provided financial support. All authors have read and approved the final manuscript.

\section{Acknowledgements}

This research was supported by the Chinese National Natural Science Foundation (Grant No.: 30671408) and the Guangdong Province Natural Science Foundation (Grant No.: 06 105204). We thank Dr. Arthur Retnakaran of Canadian Forest Service and Dr. Peter Krell of University of Guelph in Canada for their critical review and discussion of the manuscript.

\section{References}

I. Gallegos AM, Atshaves BP, Storey SM, Starodub O, Petrescu AD, Huang H, Mclntosh AL, Martin GG, Chao H, Kier AB, Schroeder F: Gene structure, intracellular localization, and functional roles of sterol carrier protein-2. Prog Lipid Res 2001, 40:498-563.

2. Vyazunova I, Lan Q: Insect sterol carrier protein-2 gene family: Structures and functions. Adv Insect Physiol Toxicol Mol Biol 2008, 37:173-198.

3. Gilbert LI, Rybczynski R, Warren JT: Control and biochemical nature of the ecdysteroidogenic pathway. Ann Rev Entomol 2002, 47:883-916.

4. Grieneisen ML: Recent advances in our knowledge of ecdysteroid biosynthesis in insects and crustaceans. Insect Biochem Mol Biol 1994, 24: II5-132.

5. Beydon P, Lafont R: Long-term cholesterol labeling as a convenient means for measuring ecdysteroid production and 
catabolism in vivo: application to the last larval instar of Pieris brassicae. Arch Insect Biochem Physiol 1987, 5:139-154.

6. Clayton RB, Hinkle PC, Smith DA, Edwards AM: The intestinal absorption of cholesterol, its esters and some related sterols and analogues in the roach, Eurycotis floridana. Comp Biochem Physiol 1964, I I:333-350.

7. Guo D, Venkatramesh M, Nes WD: Developmental regulation of sterol biosynthesis in Zea mays. J Lipid Res 1995, 30:203-219.

8. Jouni ZE, Zamora J, Wells MA: Absorption and tissue distribution of cholesterol in Manduca sexta. Arch Insect Biochem Physiol 2002, 49:167-175.

9. Ohba T, Holt JA, Billheimer JT, Strauss JF: Human sterol carrier protein $\mathrm{x} / \mathrm{sterol}$ carrier protein 2 gene has two promoters. Biochem 1995, 34: 10660-10668.

10. Seedorf U, Raabe M, Ellinghaus P, Kannenberg F, Fobker M, Engle T, Denis S, Wouters F, Wirtz KWA, Wanders RJA, Maeda N, Assmann G: Defective peroxisomal catabolism of branched fatty acyl coenzyme $A$ in mice lacking the sterol carrier protein-2 sterol carrier protein-x gene function. Genes Dev 1998, 12:|189-|201

II. Seedorf U, Assmann G: Cloning, expression, and nucleotide sequence of rat liver sterol carrier protein 2 cDNAs. J Biol Chem 1991, 266:630-636.

12. Pfeifer SM, Sakuragi N, Ryan A, Johnson AL, Deeley RG, Billheimer JT, Baker ME, Strauss JF: Chicken sterol carrier protein-2 sterol carrier protein- $x$ cDNA cloning reveals evolutionary conservation of structure and regulated expression. Arch Biochem Biophys 1993, 304:287-293.

13. Kannenberg F, Ellinghaus P, Assmann G, Seedorf U: Aberrant oxidation of the cholesterol side chain in bile acid synthesis of sterol carrier protein-2/sterol carrier protein-x knockout mice. J Biol Chem 1999, 274:35455-35460.

14. Ko MH, Puglielli L: The sterol carrier protein SCP-x/Pro-SCP. 2 gene has transcriptional activity and regulates the Alzheimer disease-secretase. J Biol Chem 2007, 28:19742-19752.

15. Yamamoto R, Kallen CB, Babalola GO, Rennert H, Billheimer JT, Strauss JF: Cloning and expression of a complementary DNA encoding human sterol carrier protein 2. Proc Natl Acad Sci |99|, 88:463-467.

16. Seedorf U, Ellinghaus P, Nofer JR: Sterol carrier protein-2. Biochim Biophys Acta 2000, I 486:45-54.

17. Tan H, Ckazaki K, Kubota I, Kamiryo T, Utiyama H: A novel peroxisomal nonspecific lipid-transfer protein from Candida tropicalis: Gene structure, purification and possible role in betaoxidation. Eur J Biochem 1990, 190:107-II2.

18. Bun-ya, Maebuchi MM, Hashimoto T, Yokota S, Kamiryo T: A second isoform of 3-oxoacyl-CoA thiolase found in Caenorhabditis elegans, which is similar to sterol carrier protein $x$ but lacks the sequence of sterol carrier protein 2. Eur J Biochem 1997, 245:252-259.

19. Kitamura T, S Kobayashi, M Okada: Regional expression of the transcript encoding sterol carrier protein $x$ related thiolaseand its regulation by homeotic genes in the midgut of Drosophila embryos. Dev Growth Differ 1996, 38:373-38I.

20. Lan Q, Wessely V: Expression of a sterol carrier protein-x gene in the yellow fever mosquito, Aedes aegypti. Insect Mol Biol 2004, I 4:519-529.

21. Takeuchi H, Chen JH, Jenkins JR, Bun-Ya M, Turner PC, Rees HH: Characterization of a sterol carrier protein 2/3-oxoacyl-CoA thiolase from the cotton leafworm (Spodoptera littoralis): a lepidopteran mechanism closer to that in mammals than that in dipterans. Biochem / 2004, 382:93-100.

22. Gong J, Hou Y, Zha XF, Lu C, Zhu Y, Xia QY: Molecular cloning and characterization of Bombyx mori sterol carrier protein $\mathbf{x}$ sterol carrier protein 2 (SCPx/SCP2) gene. DNA Seq 2006, 17:326-333

23. Atshaves BP, Petrescu AD, Starodub O, Roths JB, Kier AB, Schroeder $\mathrm{F}$ : Expression and intracellular processing of the $58 \mathrm{kDa}$ sterol carrier protein-2/3-oxoacyl-CoA thiolase in transfected mouse L-cell fibroblasts. J Lipid Res 1999, 40:61 0-622.

24. Blitzer EJ, Vyazunova I, Lan Q: Functional analysis of AeSCP-2 using gene expression knockdown in the yellow fever mosquito, Aedes aegypti. Insect Mol Biol 2005, 14:30I-307.

25. Lan Q, Massey RJ: Subcellular localization of the mosquito sterol carrier protein-2 and sterol carrier protein-x. J Lipid Res 2004, 45: | $458-1474$
26. Thompson S, Mayerl F, Peoples OP, Masamune S, Sinskey AJ, Walsh $\mathrm{CT}$ : Mechanistic study on $\beta$-oxoacyl thiolase from Zoogloea ramigera: identification of the active-site nucleophile as Cys89, its mutation to Ser89, and kinetic and thermodynamic characterization of wild-type and mutant enzymes. Biochem 1989, 28:5735-5742.

27. Weber FE, Dyer JH, López García F, Werder M, Szyperski T, Wüthrich K, Hauser H: In pre-sterol carrier protein 2 (SCP2) in solution the leader peptide I-20 is flexibly disordered, and residues $2 \mid-143$ adopt the same globular fold as in mature SCP2. Cell Mol Life Sci 1998, 54:75I-759.

28. Schroeder F, Frolov A, Starodub O, Atshaves BB, Russell W, Petrescu A, Huang H, Gallegos AM, Mclntosh A, Tahotna D, Russell DH, Billheimer JT, Baum CL, Kier AB: Pro-sterol carrier protein-2: role of the $\mathrm{N}$-terminal presequence in structure, function, and peroxisomal targeting. J Biol Chem 2000, 275:25547-25555.

29. Martin GG, Hostetler HA, Tichy SE, Russell DH, Berg JM, Woldegiorgis G, Spencer TA, Ball JM, Kier AB, Schroeder F: Structure and function of the sterol carrier protein-2 (SCP-2) N-terminal pre-sequence. Biochem 2008, 47:5915-5934.

30. Frolov A, Cho TH, Billheimer JT, Schroeder F: Sterol carrier protein-2, a new fatty acyl coenzyme A-binding protein. J Biol Chem 1996, 271:31878-31884.

31. Schroeder F, Atshaves BP, Mclntosh AL, Gallegos AM, Storey SM, Parr RD, Jefferson JR, Ball JM, Kier AB: Sterol carrier protein-2: New roles in regulating lipid rafts and signalling. Biochim Biophy Acta 2007, 1771:700-718.

32. Ferdinandusse $\mathrm{S}$, Kostopoulos $\mathrm{P}$, Denis $\mathrm{S}$, Rusch $\mathrm{H}$, Overmars H, Dillmann U, Reith W, Haas D, Wanders RJ, Duran M, Marziniak M: Mutations in the gene encoding peroxisomal sterol carrier protein X (SCPx) cause leukencephalopathy with dystonia and motor neuropathy. Am J Hum Genet 2006, 78: I046-1052.

33. Krebs KC, Lan Q: Isolation and expression of a sterol carrier protein-2 gene from the yellow fever mosquito, Aedes aegypti. Insect Mol Biol 2003, I 2:5 I-60.

34. Vyazunova I, Wessley V, Kim M, Lan Q: Identification of two sterol carrier protein-2 like genes in the yellow fever mosquito, Aedes aegypti. Insect Mol Biol 2007, 16:305-3।4.

35. Vila A, Levchenko VV, Korytowski W, Girotti AW: Sterol carrier protein-2-facilitated intermembrane transfer of cholesteroland phospholipid-derived hydroperoxides. Biochemistry 2004, 43: $12592-12605$

36. Moncecchi D, Murphy EJ, Prows DR, Schroeder F: Sterol carrier protein-2 expression in mouse L-cell fibroblasts alters cholesterol uptake. Biochim Biophys Acta 1996, I302: I 10-1 16.

37. Zdobnov EM, Mering C, Letunic I, Torrents D, Suyama M, Copley RR: Comparative genome and proteome analysis of Anopheles gambiae and Drosophila melanogaster. Science 2002, 298: $149-159$.

38. Langley PA, Ogwal LM, Felton T, Stafford K: Lipid digestion in the tsetse fly, Glossina morsitans. J Insect Physiol 1987, 33:98I-986.

39. Kuthiala A, Ritter KS: Esterification of cholesterol and cholestanol in the whole body, tissues, and frass of Heliothis zea. Arch Insect Biochem Physiol 1988, 7:237-248

40. Komnick H, Giesa U: Intestinal absorption of cholesterol, transport in the haemolymph, and incorporation into the fat body and Malpighian tubules of the larval dragonfly Aeshna cyanea. Comp Biochem Physiol 1994, 107:553-557.

4I. Ritter KS, Nes WR: The effects of cholesterol on the development of Heliothis zea. J Insect Physiol I98I, 27: I75-182.

42. Nes WD, Lopez M, Zhou W, Guo D, Dowd PF, Norton RA: Sterol utilization and metabolism by Heliothis zea. J Lipid Res 1997, 32:1317-1323.

43. Dansen TB, Kops GJ, Denis S, Jelluma N, Wanders RJ, Bos JL, Burgering BM, Wirtz KW: Regulation of sterol carrier protein gene expression by the forkhead transcription factor FOXO3a. Lipid Res 2003, 45:8I-88.

44. Lan Q, Gerenday A, Fallon AM: Cultured Aedes albopictus mosquito cells synthesize hormone-inducible proteins. In Vitro Cell Dev Biol Anim 1993, 29A:813-818.

45. Altschul SF, Gish W, Miller W, Myers EW, Lipman DJ: Basic local alignment search tool. J Mol Biol 1990, 5:403-4I0.

46. Higgins DG, Sharp PM: CLUSTAL: a package for performing multiple sequence alignment on a microcomputer. Gene 1988, 15:237-244. 
47. Béliveau C, Laforge M, Cusson M, Bellemare G: Expression of a Tranosema rostrale polydnavirus gene in the spruce budworm, Choristoneura fumiferana. J Gen Virol 2000, 8I: $|87|-\mid 880$.

48. Feng QL, Davey KG, Pang AD, Ladd TR, Retnakaran A, Tomkins BL, Zheng S, Palli SR: Developmental expression and stress induction of glutathione $S$-transferase in the spruce budworm, Choristoneura fumiferana. J Insect Physiol 200I, 47:I-I0.

Publish with Bio Med Central and every scientist can read your work free of charge

"BioMed Central will be the most significant development for disseminating the results of biomedical research in our lifetime. " Sir Paul Nurse, Cancer Research UK

Your research papers will be:

- available free of charge to the entire biomedical community

- peer reviewed and published immediately upon acceptance

- cited in PubMed and archived on PubMed Central

- yours - you keep the copyright

Submit your manuscript here:

http://www.biomedcentral.com/info/publishing_adv.asp
BioMedcentral 